\title{
Peripheral neuropathy in chronic liver disease : clinical, electrodiagnostic, and nerve biopsy findings
}

\author{
R. P. KNILL-JONES, C. J. GOODWILL, A. D. DAYAN, \\ AND ROGER WILLIAMS \\ From the Medical Research Council Group on Metabolism and Haemodynamics of Liver Disease, \\ Department of Physical Medicine and Rheumatology, King's College Hospital, \\ and the Department of Neuropathology, Institute of Neurology, London
}

SUMMARY In a prospective study of 70 unselected patients with chronic liver disease, clinical signs of a peripheral neuropathy were observed in 13 patients. Abnormal nerve conduction was demon- $\overrightarrow{0}$ strated in nine of these and in one further patient who had no abnormal neurological signs. The $\overrightarrow{-}$ occurrence of a neuropathy (in patients with cryptogenic cirrhosis, haemochromatosis, active chronic $\tilde{\sigma}^{\circ}$ hepatitis as well as in alcoholic cirrhosis) could not be related to liver function, although it was associated with higher $\operatorname{IgA}$ and $\operatorname{IgM}$ values. Clinical diabetes was present in six of the 14 patientso with neuropathy but there was no relation in the non-diabetic patients between neuropathy and $\dot{c}_{\tilde{J}}^{\mathbf{w}}$ minor impairment of carbohydrate tolerance. Those with neuropathy had a significantly higher $-\dot{-}$ incidence of oesophageal varices and there was also a relationship to a history of previous encephale्बin pathy. Sural nerve biopsy was carried out on 14 patients, eight of whom had clinical or electrö-응 diagnostic evidence of neuropathy. Single nerve fibres were examined by teasing and in all nerv\&s histological evidence was found of an indolent process which had damaged whole Schwann ce $\$$ s and which resulted in demyelination and remyelination. Diabetic angiopathy was not seen and axongle degeneration, which was never severe, was found in all disease groups equally.

The occurrence of a demyelinating peripheral neuropathy in liver disease was first described by Dayan and Williams (1967). Six of their 10 patients had clinical signs of nerve damage including absent reflexes and impairment of vibration sense or touch, although a biopsy of the sural nerve showed active segmental demyelination in all. This type of Schwann cell disease also occurs in the neuropathy of diabetes and other conditions (Thomas and Lascelles, 1966; Gilliatt, 1969; Dayan, Gardner-Thorpe, Down, and Gleadle, 1970), but is distinct from the histological changes of axonal degeneration usually seen in alcoholism (Victor, 1965). The cause of the segmental demyelination observed in the patients with liver disease was not established and the present study was undertaken to determine the frequency of peripheral nerve damage in a larger series of patients who were investigated by electrodiagnostic techniques as well as clinically and by sural nerve biopsy. A possible relationship to the biochemical changes, including disturbances of carbohydrate metabol- ism, which accompany liver disease was also examined.

\section{METHODS}

Seventy patients (36 males, 34 females) with histologically proven cirrhosis or active chronic hepatitis were questioned for symptoms indicative of peri pheral neuropathy-namely, distal sensory loss paraesthesiae, clumsiness, or weakness. Examination of the peripheral nervous system included theo appreciation of light touch, pinprick, and two-point? discrimination. Alteration in vibration sense was. sought by timing the duration of perception of aO tuning fork (frequency $128 / \mathrm{sec}$ ) placed on the olecranon, second metacarpophalangeal joint, tibia $\mathrm{P}$ tubercles, and medial malleoli. Isolated loss or reduction of ankle jerks in patients more than 60 . years old was not considered abnormal.

The laboratory investigations included a blood count and liver function tests, and in 48 patients the serum immunoglobulins. In the first 23 patients serum $\mathbf{B}_{12}$ and folate levels were measured and the bone marrow examined. An oral glucose toleranceo 
test (50 $\mathrm{g}$ load) was also carried out except in those patients known to be diabetic.

ELECTRODIAGNOSTIC TECHNIQUES Nerve conduction velocities were measured in both lateral popliteal nerves stimulating at the head of the fibula and at the ankle. Velocities were also obtained for the upper and lower segments of left median and ulnar nerves by stimulating at the axilla, elbow, and wrist. Bipolar electrodes of $8 \mathrm{~mm}$ diameter carrying a square electrical pulse of $0.1 \mathrm{msec}$ duration were used for stimulation, and for recording surface electrodes were placed over the extensor digitorum brevis muscle in the foot, and the thenar and hypothenar muscles in the hand. Electromyograms were obtained from a concentric needle electrode inserted into the first dorsal interosseous muscle in each hand, and in the tibialis anterior and extensor digitorum brevis muscle in each foot. The temperature of the examination room was more than $65^{\circ} \mathrm{F}\left(18.3^{\circ} \mathrm{C}\right)$. The electrodiagnostic investigations were carried out without knowledge of the clinical findings.

Peripheral neuropathy was considered to be present if there was significant slowing of motor nerve conduction in one nerve $(30 \mathrm{~m} / \mathrm{sec}$ in the lateral popliteal nerves, and $40 \mathrm{~m} / \mathrm{sec}$ in the median or ulnar nerves). Spontaneous fibrillation and positive potentials in the electromyogram with the muscle at rest, and a reduced interference pattern on maximal voluntary effort were regarded as evidence of denervation but were not considered diagnostic of a neuropathy unless slowing of motor nerve conduction was also present.

\section{RESULTS}

Clinical signs of neuropathy were found in 13 of the 70 patients, although only two complained of paraesthesiae and weakness. The most common abnormalities were impairment of vibration sense in the legs-present in 13 patients-and impairment of superficial sensation in a 'glove and stocking' distribution which was found in seven patients. The ankle reflexes were absent on both sides or obtainable only with reinforcement in seven patients, in four of whom there was also impairment or absence of knee jerks. Motor weakness of the limbs (M.R.C. grade 4) was found in five patients.

Nine of these patients with clinical neuropathy also showed electrodiagnostic evidence of neuropathy. In addition, there was one other patient with significant changes in motor nerve conduction but without clinical evidence of neuropathy, making a total of 14 patients in the series with clinical and/or electrodiagnostic evidence of a peripheral neuropathy. The relevant clinical data for these 14 patients are given in Table 1 . In none was there clinical evidence of severe arterial disease.

Neuropathy was found most frequently in alcoholic cirrhosis and haemochromatosis (Table 2) but the numbers in some of the aetiological groups were relatively small. None of the patients with haemochromatosis had had a history of significant alcohol intake. The patient with the most severe neuropathy had active chronic hepatitis, and is described in more detail later.

A comparison of those with and without neuropathy revealed no significant differences in the liver function tests except for changes in serum immunoglobulins (Table 3). IgA and IgM were considerably higher in those with evidence of neuropathy and the elevation of IgM (to more than twice the level in the patients without neuropathy) reached statistical significance $(P<0.05)$. These alterations in immunoglobulin levels were independent of the type of cirrhosis, and the patients with neuropathy when considered together had higher mean IgA and IgM values than those found in any individual disease group.

Seven $(50 \%)$ of the 14 patients with neuropathy showed either oesophageal varices on barium swallow examination or had had a portacaval shunt, a significantly higher incidence than in the patients with normal conduction, $27 \%$ of whom had varices $(P<0.05)$. There was also a similar correlation with a past history of hepatic encephalopathy, seven $(50 \%)$ of the patients with neuropathy having had previous episodes of encephalopathy as compared with five $(9 \%)$ of the 56 patients without neuropathy $(\mathrm{P}<0.001)$. No patient showed features of hepatic encephalopathy at the time of the study.

RELATION TO IMPAIRED CARBOHYDRATE TOLERANCE Of the 14 patients with a peripheral neuropathy, six were known to have diabetes. The severity of the neuropathy bore no relationship to the duration of diabetes. In four patients diabetes had been diagnosed more than 10 years previously, whereas in the other two patients with an equally severe neuropathy diabetes had been present for only six months. Both of these patients had also had episodes of portosystemic encephalopathy, which may have contributed to their neuropathy. Of the 56 patients without neuropathy four had diabetes, a significantly lower incidence $(P<0 \cdot 01)$.

Sixteen of the patients who did not have 


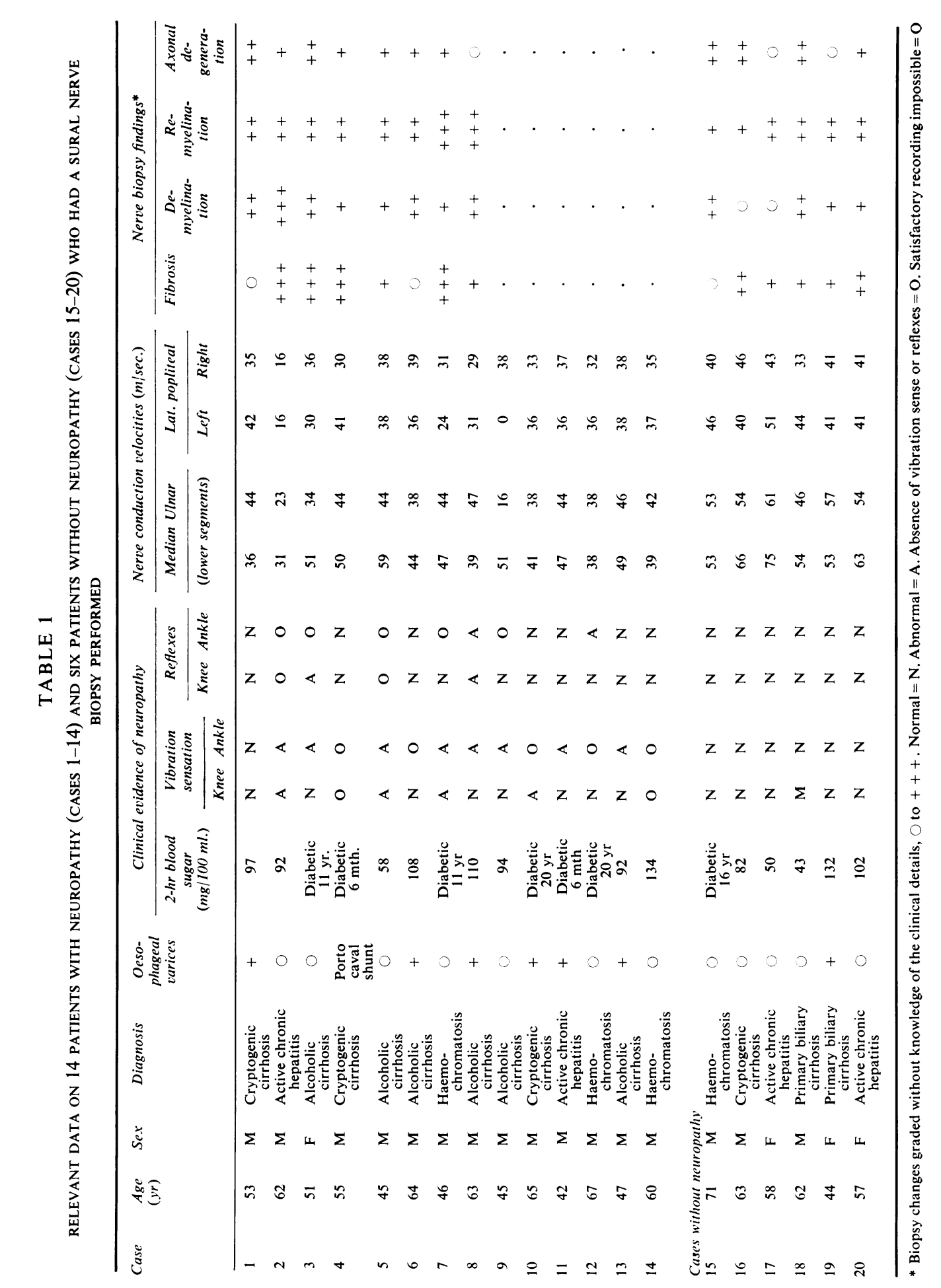

c

$\stackrel{\omega}{\omega}$

무유

ब일

要

एक

응

훌

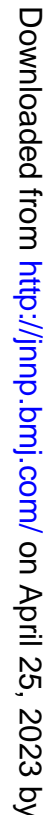

@ 
TABLE 2

INCIDENCE OF NEUROPATHY IN THE DIFFERENT GROUPS

\begin{tabular}{lcc}
\hline Diagnosis & Patients $($ no. $)$ & Neuropathy \\
\hline Active chronic hepatitis & 26 & 2 \\
Alcoholic cirrhosis & 13 & 6 \\
Cryptogenic cirrhosis & 12 & $3^{*}$ \\
Primary biliary cirrhosis & 12 & 0 \\
Haemochromatosis & 7 & 3 \\
\hline Total & 70 & 14 \\
\hline
\end{tabular}

* One of these patients had electrodiagnostic evidence of neuropathy only.

TABLE 3

COMPARISON OF CLINICAL FEATURES, BIOCHEMICAL AND HAEMATOLOGICAL FINDINGS IN PATIENTS WITH (14) AND WITHOUT (56) EVIDENCE OF A PERIPHERAL NEUROPATHY

\begin{tabular}{lcc}
\hline & Normal & Neuropathy \\
\hline Age: & & \\
Mean (yr) & $51 \pm 2 \cdot 1$ & $55 \pm 2 \cdot 5$ \\
Range (yr) & $14-79$ & $45-67$ \\
Duration of disease (months) & $27 \pm 3$ & $28 \pm 8$ \\
Total bilirubin (mg/100 ml.) & $3 \cdot 1 \pm 0 \cdot 6$ & $1 \cdot 2 \pm 0 \cdot 2$ \\
Aspartate aminotransferase (u./100 ml.) & $77 \pm 12 \cdot 2$ & $54 \pm 7 \cdot 7$ \\
Alkaline phosphatase (K.A. u./100 ml.) & $26 \pm 3 \cdot 3$ & $15 \pm 2 \cdot 5$ \\
Albumin (g/100 ml.) & $2 \cdot 9 \pm 0 \cdot 1$ & $2 \cdot 8 \pm 0 \cdot 1$ \\
Total globulin (g/100 ml.) & $4 \cdot 6 \pm 0 \cdot 2$ & $4 \cdot 1 \pm 0 \cdot 4$ \\
Immunoglobulins (mg/100 ml.) & & \\
IgG & $2033 \pm 148$ & $1797 \pm 188$ \\
IgA & $470 \pm 466$ & $785 \pm 308$ \\
IgM & $223 \pm 274$ & $539 \pm 312$ \\
B $(\mu \mu / \mathrm{ml})$. & $568 \pm 54$ & $627 \pm 74$ \\
Folate (m $\mu / \mathrm{ml})$. & $5 \cdot 3 \pm 0 \cdot 7$ & $5 \cdot 2 \pm 0 \cdot 6$ \\
& & \\
Carbohydrate tolerance (diabetic & & \\
patients excluded) & & \\
Blood sugar (mg/100 ml.) & & \\
fasting & & \\
$\frac{1}{2} \mathrm{hr}$ & & \\
1 hr & $125 \pm 4 \cdot 5$ & $122 \pm 10 \cdot 5$ \\
$1 \frac{1}{2}$ hr & $140 \pm 6 \cdot 1$ & $164 \pm 16 \cdot 0$ \\
2 hr & $123 \pm 6 \cdot 3$ & $137 \pm 12 \cdot 0$ \\
\hline & $104 \pm 6 \cdot 5$ & $97 \pm 9 \cdot 0$ \\
\hline
\end{tabular}

Mean values are given \pm standard error of the mean.

clinical diabetes were found to have an impaired glucose tolerance test (defined as a two-hour blood sugar level higher than $120 \mathrm{mg} / 100 \mathrm{ml}$.). In each case the fasting level was below $100 \mathrm{mg} /$ $100 \mathrm{ml}$. One had a neuropathy and $15 \mathrm{did}$ not, giving a similar incidence in both groups of patients. Comparison of the patients with a raised two-hour blood sugar level and those with a normal level revealed no significant differences in nerve conduction velocities, latencies, or vibration perception times (Table 4). Thus, if the patients with clinical diabetes are excluded, there is no relationship in the remainder between neuropathy and minor impairment of glucose tolerance.

SURAL NERVE BIOPSY This was obtained under local anaesthesia in 12 patients and at necropsy
TABLE 4

COMPARISON OF MEAN NERVE CONDUCTION VELOCITIES, MOTOR LATENCIES, AND DURATION OF VIBRATION PERCEPTION IN 44 PATIENTS WITH NORMAL GLUCOSE TOLERANCE, 16 WITH MINOR ABNORMALITIES OF GLUCOSE TOLERANCE AND 10 WITH DEFINITE DIABETES

\begin{tabular}{|c|c|c|c|c|}
\hline & & \multicolumn{2}{|c|}{ Blood sugar at $2 \mathrm{hr}$} & \multirow[t]{2}{*}{ Diabetes } \\
\hline & & Normal & Abnormal & \\
\hline Nerie & Segment & \multicolumn{3}{|c|}{ Nerve conduction velocity $(\mathrm{m} / \mathrm{sec})$} \\
\hline $\begin{array}{l}\text { Median } \\
\text { Ulnar } \\
\text { Lateral } \\
\text { popliteal }\end{array}$ & $\begin{array}{l}\text { Upper } \\
\text { Lower } \\
\text { Upper } \\
\text { Lower } \\
\text { Left } \\
\text { Right }\end{array}$ & $\begin{array}{l}62 \pm 1 \cdot 5 \\
52 \pm 0 \cdot 9 \\
58 \pm 1 \cdot 8 \\
55 \pm 1 \cdot 5 \\
44 \pm 1 \cdot 3 \\
43 \pm 1 \cdot 0\end{array}$ & $\begin{array}{l}55 \pm 1 \cdot 4 \\
52 \pm 2 \cdot 0 \\
60 \pm 1 \cdot 5 \\
53 \pm 1 \cdot 8 \\
45 \pm 2 \cdot 7 \\
44 \pm 2 \cdot 8\end{array}$ & $\begin{array}{l}51 \pm 4 \cdot 9 \\
49 \pm 1 \cdot 8 \\
50 \pm 2 \cdot 2 \\
47 \pm 2 \cdot 6 \\
40 \pm 2 \cdot 8 \\
39 \pm 2 \cdot 1\end{array}$ \\
\hline Nerce & $\begin{array}{l}\text { Point of } \\
\text { stimulation }\end{array}$ & \multicolumn{3}{|c|}{ Mean latencies $(\mathrm{m} / \mathrm{sec})}$. \\
\hline $\begin{array}{l}\text { Median } \\
\text { Ulnar } \\
\text { Left lateral } \\
\text { popliteal } \\
\text { Right lateral }\end{array}$ & $\begin{array}{l}\text { Wrist } \\
\text { Wrist } \\
\text { Ankle } \\
\text { Ankle }\end{array}$ & $\begin{array}{l}3 \cdot 7 \pm 1 \cdot 2 \\
3 \cdot 2 \pm 1 \cdot 1 \\
5 \cdot 6 \pm 2 \cdot 7 \\
5 \cdot 6 \pm 2 \cdot 2\end{array}$ & $\begin{array}{l}3 \cdot 3 \pm 2 \cdot 2 \\
3 \cdot 3 \pm 2 \cdot 1 \\
5 \cdot 3 \pm 3 \cdot 3 \\
5 \cdot 3 \pm 3 \cdot 8\end{array}$ & $\begin{array}{l}3 \cdot 8 \pm 2 \cdot 6 \\
3 \cdot 3 \pm 2 \cdot 6 \\
6 \cdot 2 \pm 5 \cdot 3 \\
6 \cdot 1 \pm 4 \cdot 3\end{array}$ \\
\hline \multicolumn{5}{|c|}{$\begin{array}{l}\text { Average of left and right } \\
\text { vibration duration (sec.) }\end{array}$} \\
\hline $\begin{array}{l}\text { Elbow } \\
\text { MP joint } \\
\text { Knee } \\
\text { Ankle }\end{array}$ & & $\begin{array}{r}12 \pm 0.9 \\
16 \pm 1 \cdot 1 \\
9 \pm 0.8 \\
10 \pm 0.9\end{array}$ & $\begin{array}{r}11 \pm 1 \cdot 5 \\
15 \pm 1 \cdot 8 \\
9 \pm 1 \cdot 4 \\
9 \pm 1 \cdot 1\end{array}$ & $\begin{array}{r}11 \pm 2 \cdot 3 \\
14 \pm 1 \cdot 3 \\
5 \pm 1 \cdot 9 \\
3 \pm 2 \cdot 0\end{array}$ \\
\hline
\end{tabular}

Mean \pm 1 SE of mean.

in two patients. Biopsies were obtained from seven of the 13 patients with clinical evidence of neuropathy and from one patient with abnormal conduction velocities only (Table 1$)$. The remaining six biopsies were from patients without definite evidence of neuropathy.

All 14 biopsies showed some histological abnormalities, although these varied considerably in severity from case to case. No definite lesions were found in the nerves in standard sections, although there were apparent differences in the amount of endoneurial fibrous tissue and in the relative proportions of the larger and smaller diameter myelinated nerve fibres. Small blood vessels in the perineural spaces appeared normal and did not show hyalinization of their walls or thickening or reduplication of the basement membranes. Only a very occasional degenerating fibre was seen in frozen sections stained to show myelin sheaths; this was no more frequent in the patients with alcoholic cirrhosis than in the other diagnostic groups.

Isolated nerve fibres separated by freehand 'teasing' showed two main types of damage. The commonest was the presence along fibres of partly or completely demyelinated internodes- 


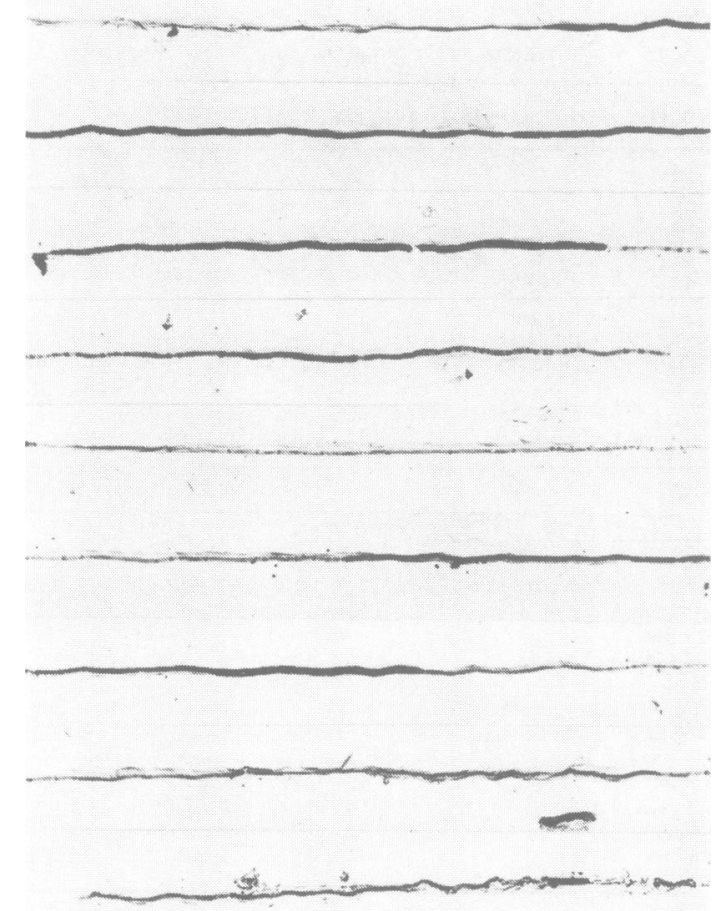

FIG. 1a. Consecutive lengths of a teased nerve fibre showing many short, thin, re-myelinated internodes formed after extensive segmental demyelination (from case 17, Table 1).
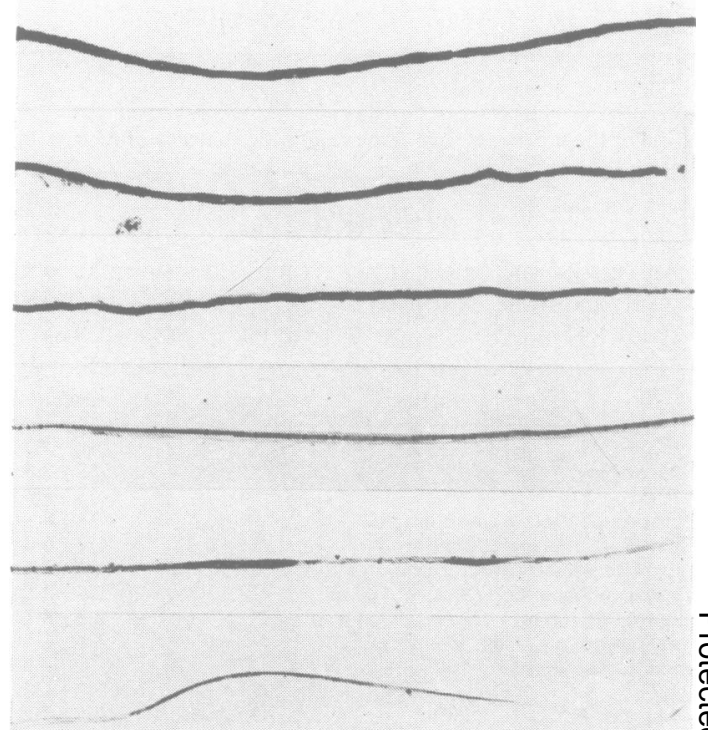

FIG. $1 \mathrm{~b}$ Similar to $1 \mathrm{a}$. In addition, there are some denuded areas due to the presence of active Schwann cell-myelin damage (from case 3, Table 1).

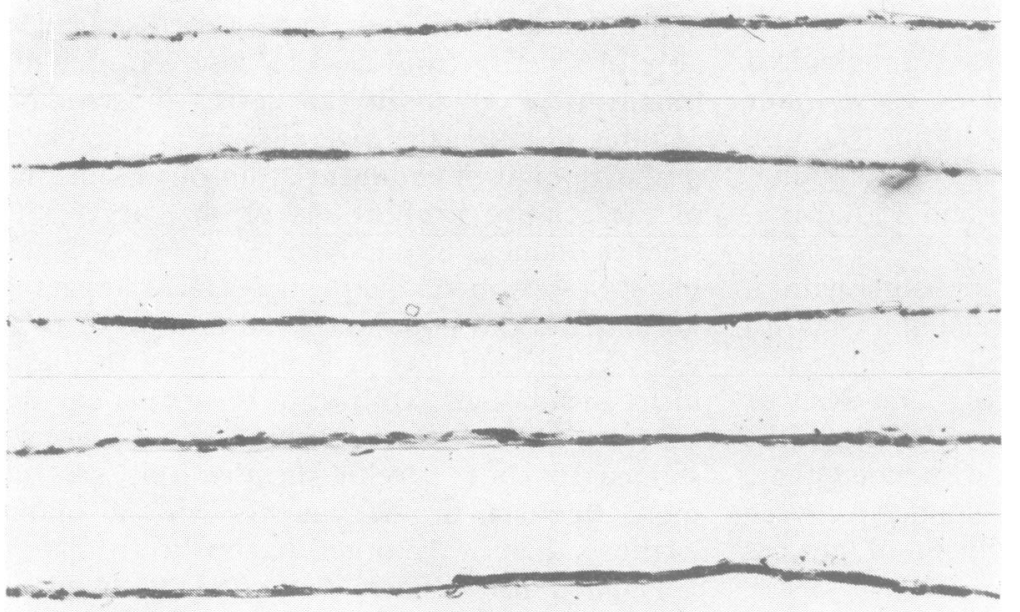

FIG. 1c. Consecutive lengths of a teased nerve fibre showing granular debris due to complete, Wallerian-type degeneration (from case 18, Table 1). 
'segmental demyelination'-together with the results of healing of this lesion-chains of uniformly too-short segments interspersed between internodes of normal length (Fig. 1). Such healed (or healing) lesions were more frequent than actively breaking down myelin, and the reparative processes appeared to be following the normal pattern.

No evidence was seen of excessive proliferation of Schwann cells forming 'onion bulbs', or of excessive accumulation of myelin breakdown products. The other type of damage, 'Wallerianlike' or 'total' nerve fibre degeneration, in which both axis cylinders and their myelin sheaths are destroyed, was seen less often (10 biopsies), particularly in the acute stage of a long chain of osmiophilic globules, or as a Schwann cell tube forming a band of Brüngner. Healing of this process, which is necessarily slow because it requires regrowth of an axonal sprout, eventually produces fibres which bear stoutly myelinated internodes uniformly too short for a normal fibre of that diameter. The latter type of abnormal nerve fibre was relatively more frequent in the present biopsies than acutely degenerating forms. The overall impression was of an indolent type of pathological process, sometimes quite extensive and severe (more than $50 \%$ of teased fibres were abnormal in some cases), which had produced greater damage to the Schwann cellmyelin complex than to the axis cylinders. Restricted paranodal lesions of the myelin sheath were very uncommon, suggesting that whatever had damaged the nerves had done so with such an intensity, or for such a duration, that entire Schwann cells had degenerated, rather than just their most distal and labile tips.

The data for the internodal-length relationship in four patients has been plotted for each fibre according to the convention of Fullerton,
Gilliatt, Lascelles, and Morgan-Hughes (1965), in which individual segments on an isolated fibre are represented by points on a vertical line (Fig. 2). Comparison with normal values (Thomas and Lascelles, 1966) shows how very extensive the damage was in some patients, and how much more common were features of Schwann cellmyelin lesions than complete nerve fibre degeneration.

No relationship could be found between the histological changes in the nerves and the presence or absence of diabetes or oesophageal varices (Table 1).

\section{SERIAL OBSERVATIONS AND RESPONSE TO TREATMENT IN TWO PATIENTS}

CASE 1 (Table 1) This male patient had been noted to have splenomegaly at the age of 9 years during an attack of jaundice. However, he remained well until the age of 52 when he presented with ankle oedema and mild portosystemic encephalopathy. Radiological examination showed an extensive collateral circulation (Blendis, Laws, Williams, and Thompson, 1968). The glucose tolerance test was normal. There were no signs of clinical neuropathy but the conduction velocities were reduced in both arms and legs and there was electromyographic evidence of denervation. Sural nerve biopsy showed active and healed demyelination with some loss of nerve fibres. The patient was treated with neomycin and a restricted protein diet with return of conduction velocities to normal over an 18 month period (Table 5).

CASE 2 (Table 1) A sales manager aged 62 years presented with an eight-month history of unsteadiness of gait and numbness in the legs and fingers. He denied excessive intake of alcohol but

TABLE 5

NERVE CONDUCTION VELOCITIES AND ELECTROMYOGRAM CHANGES IN TWO PATIENTS DESCRIBED IN DETAIL IN TEXT

\begin{tabular}{|c|c|c|c|c|c|c|c|c|}
\hline & \multicolumn{6}{|c|}{ Conduction velocities $(\mathrm{m} / \mathrm{sec})$} & \multicolumn{2}{|c|}{ Electromyogram abnormality } \\
\hline & \multicolumn{2}{|c|}{ Left median nerve } & \multicolumn{2}{|c|}{ Left ulnar nerve } & \multicolumn{2}{|c|}{ Lat. popliteal nerve } & \multirow[t]{2}{*}{ At rest } & \multirow[t]{2}{*}{ Volitional } \\
\hline & Upper & Lower & Upper & Lower & Left & Right & & \\
\hline $\begin{array}{l}\text { Case 1 } \\
\text { Jan. } 1968 \\
\text { June } 1968 \\
\text { June } 1969\end{array}$ & $\begin{array}{l}43 \\
58 \\
64\end{array}$ & $\begin{array}{l}36 \\
50 \\
59\end{array}$ & $\begin{array}{l}52 \\
57 \\
57\end{array}$ & $\begin{array}{l}44 \\
47 \\
63\end{array}$ & $\begin{array}{l}42 \\
57 \\
40\end{array}$ & $\begin{array}{l}35 \\
40 \\
49\end{array}$ & $\begin{array}{l}\text { Yes } \\
\text { No } \\
\text { No }\end{array}$ & $\begin{array}{l}\text { Yes } \\
\text { Yes } \\
\text { No }\end{array}$ \\
\hline $\begin{array}{l}\text { Case 2 } \\
\text { Feb. } 1968 \\
\text { July } 1968 \\
\text { Aug. } 1969\end{array}$ & $\begin{array}{l}24 \\
33 \\
44\end{array}$ & $\begin{array}{l}31 \\
40 \\
35\end{array}$ & $\begin{array}{l}20 \\
30 \\
36\end{array}$ & $\begin{array}{l}23 \\
30 \\
30\end{array}$ & $\begin{array}{l}16 \\
24 \\
24\end{array}$ & $\begin{array}{l}16 \\
20 \\
19\end{array}$ & $\begin{array}{l}\text { Yes } \\
\text { Yes } \\
\text { No }\end{array}$ & $\begin{array}{l}\text { Yes } \\
\text { Yes } \\
\text { No }\end{array}$ \\
\hline
\end{tabular}



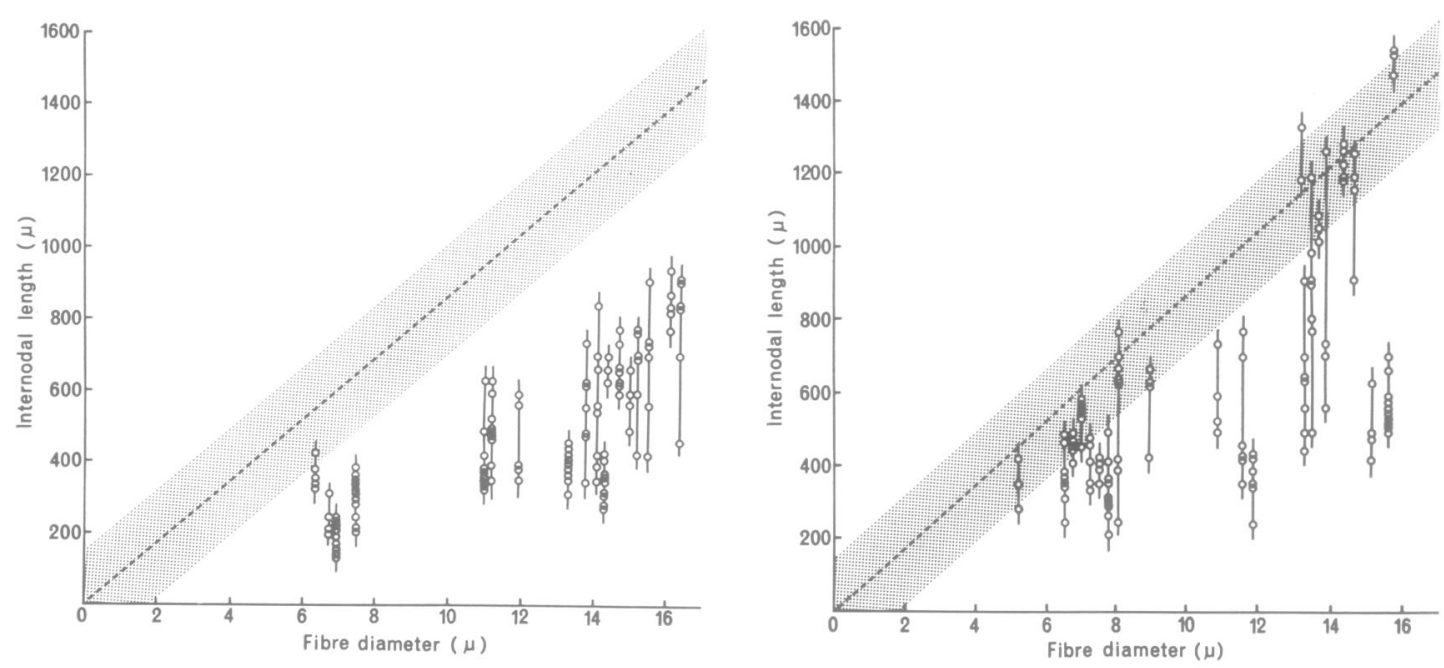

CASE 1

CASE 4
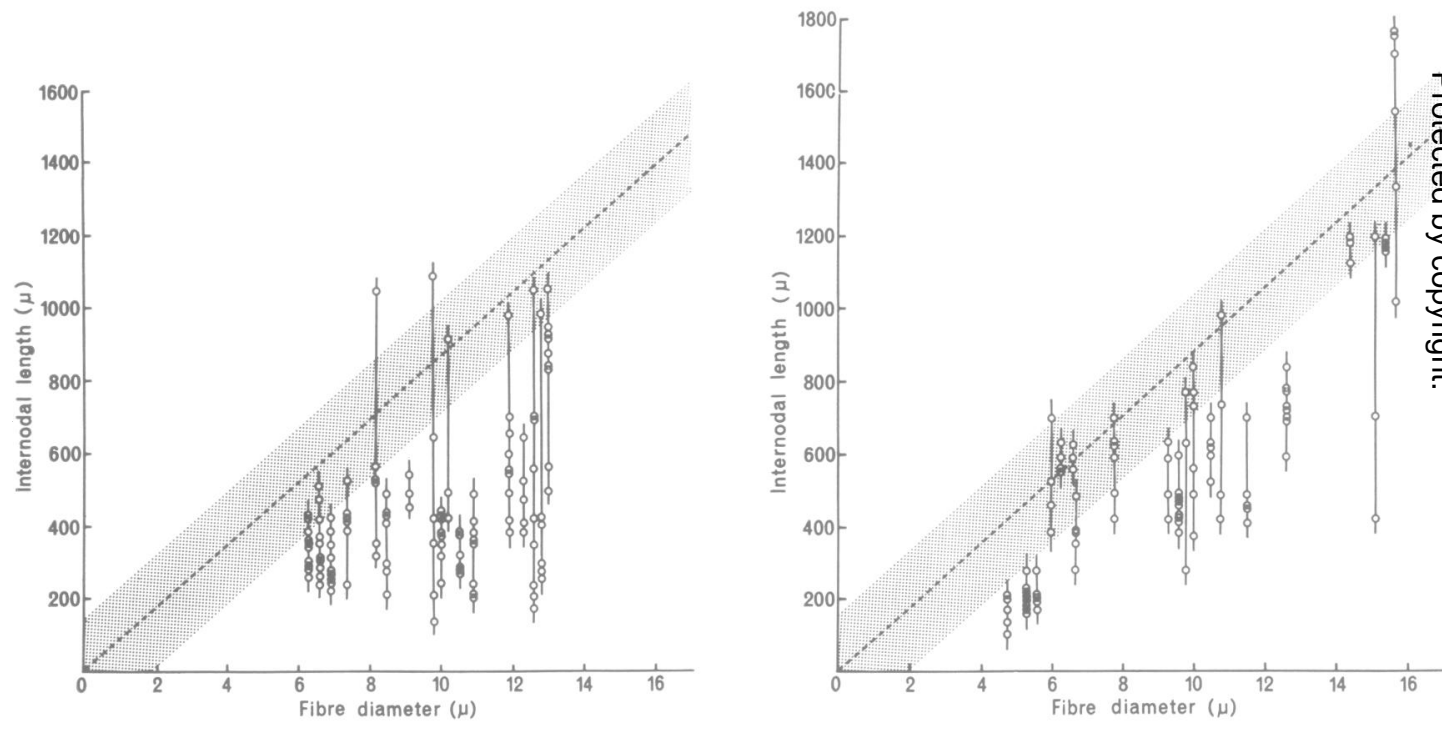

CASE 2

CASE 5

FIG. 2. Graphical analysis of sural nerve from cases 1, 2, 4, and 5 (Table 1). Each vertical line represents one fibre; the wide scatter of internodal lengths is due to segmental demyelination and remyelination. Shaded area encloses mean and 95\% confidence limits (Thomas and Lascelles, 1966).

gave a history suggestive of infective hepatitis with apparently complete recovery at the age of 38 years. Liver function tests and liver biopsy appearances were consistent with a diagnosis of active chronic hepatitis. On examination there were absent leg reflexes, marked wasting, and greatly impaired vibration and position sense in both arms and legs, with marked impairment of superficial sensation below the knees. Oesopha- geal varices were not detected; serum $\mathrm{B}_{12}$ and folate levels as well as a pyruvate tolerance curve were all normal.

Sural nerve biopsy showed a severe degree of active demyelination with some healed lesions or and also some evidence of fibre loss. Conduction $\mathbb{N}$ velocities and the electromyogram were grossly $\tilde{\omega}^{N}$ abnormal (Table 5). The patient's symptoms of neuropathy improved with azathioprine but, $\stackrel{0}{\circ}$ 
because of nausea, treatment was later changed to prednisone $(20 \mathrm{mg} / \mathrm{day})$. Conduction velocities improved further and after one year of treatment the knee reflex had returned and after a further six months, the ankle reflex also. Liver function tests improved during this period but the glucose tolerance tests became increasingly abnormal, probably as a result of prednisone therapy.

\section{DISCUSSION}

The present study confirms the earlier findings of Dayan and Williams (1967) in showing the frequent presence of segmental demyelination in patients with liver disease-indeed, it was present in every sural nerve biopsy examined. Clinical signs of a neuropathy were less frequent $-19 \%$ of the patients in the present series. Ortiz Vásquez, Olmo, Muro, Villamol, and Barreiro, 1967 have also reported clinically evident neuropathy in hepatic failure but many of their patients were alcoholics and no information is given as to the presence of diabetes. Malkova (1967) found 11 patients with a peripheral neuropathy among 242 patients with liver or gall-bladder disease in Moscow. No patient had a significant alcohol intake and all those with a neuropathy had spider naevi and purpura; seven had hypergammaglobulinaemia. The only case reported in detail had a painful peripheral neuropathy in one arm and later in one leg with an isolated blood sugar of $122 \mathrm{mg} /$ $100 \mathrm{ml}$. It is possible that this was diabetic mononeuritis, a type of neuropathy we have not yet seen in liver disease.

The occurrence of peripheral neuropathy in the present group of patients could be only partly accounted for by known causes such as alcoholism and diabetes. Furthermore, the histological abnormalities in the patients with either diabetes or alcoholism were similar to those seen in the patients in whom these factors could not be incriminated. Neither the smallvessel disease frequently seen in the nerves in diabetes nor the axonal degeneration of alcoholism was prominent. Indeed, the similarity of the histological picture in all 14 patients examined suggests that another factor common to all patients was the main cause of the neuropathy. The importance of collateral shunting was clearly shown and even in the cirrhotic patients with diabetes and in the alcoholics this may be the more important factor. The two patients with a severe neuropathy and collateral shunting who had only recently developed diabetes are a good illustration of this. Collateral shunting allows toxic factors, normally produced in the colon and detoxicated by the liver, access to both central and peripheral nervous tissue (Victor, Adams, and Cole, 1965; Cavanagh and $\mathrm{Kyu}, 1969$ ). Not surprisingly this correlates with periods of encephalopathy and this aetiological relationship is further supported by the improvement in conduction velocities seen in case 1 during protein restriction.

In one series of cirrhotic patients from Great Britain, diabetes was present in $32 \%$ and abnormal glucose tolerance was found in a further $25 \%$ of patients (Megyesi, Samols, and Marks, 1967). The impairment of glucose tolerance is associated with relative hyperinsulinism but the exact cause is unknown. Although in our patients there was a higher incidence of neuropathy in those with clinical diabetes than in those without, there was no correlation between neuropathy and minor abnormalities of glucose tolerance. This finding is in agreement with the recent study of Seneviratne and Peiris (1970) who showed that electrodiagnostic evidence of neuropathy was common in a group of patients with chronic liver disease selected because of a normal glucose tolerance test.

Advancing age is itself associated with clinical (Mayne, 1965) and pathological evidence (Lascelles and Thomas, 1966) of damage to peripheral nerves for reasons which are not known. In the present series 13 of the 18 patients with neuropathy were less than 60 years old, the age beyond which 'physiological' nerve damage becomes apparent clinically. Furthermore, the severity of the clinical signs and the extent of the nerve lesions in some of the older patients were greater than could be due to ageing alone (Arnold and Harriman, 1970).

There was no relationship between the occurrence of neuropathy and the duration of liver disease, or the changes in liver function tests. The high IgA and IgM levels are of interest but the association may simply indicate that neuropathy is related to an 'active' stage of cirrhosis as illustrated by case 2 . In this patient the neuropathy improved on corticosteroid treatment simultaneously with improvement in the biochemical changes of active chronic hepatitis. Other organs including skin, lungs, and colon are not infrequently involved in this condition, such multi-system involvement implying an 
'abnormal immune system' in this patient. The findings in case 2 would suggest that the peripheral nerves can be added to the list of organs sometimes involved in this disease. Alternatively, the immunoglobulin abnormalities may be more directly related to the cause of the nerve damage, for neuropathy is found in patients with various types of paraproteinaemias (Logothetis, Kennedy, Ellington, and Williams, 1968) and is common in patients with myeloma (Morley and Schwieger, 1968). Unfortunately, the histological appearances themselves give no clue to the aetiology of the neuropathy in our patients, although they do suggest that the final common path is Schwann cell damage.

\section{REFERENCES}

Arnold, N., and Harriman, D. G. F. (1970). The incidence of abnormality in control human peripheral nerves studied by single axon dissection. Journal of Neurology, Neurosurgery and Psychiatry, 33, 55-61.

Blendis, L. M., Laws, J. W., Williams, R., and Thomson, W. B. (1968). Calcified collateral veins and gross dilatation of the azygos vein in cirrhosis. British Journal of Radiology, 41, 909-912.

Cavanagh, J. B., and Kyu, M. H. (1969). Colchicine-like effect on astrocytes after portacaval shunt in rats. Lancet, 2 , 620-622.

Dayan, A. D., and Williams, R. (1967). Demyelinating peripheral neuropathy and liver disease. Lancet, 2, 133-134.

Dayan, A. D., Gardner-Thorpe, C., Down, P. F., and Gleadle, R. I. (1970). Peripheral neuropathy in uremia. Pathological studies on peripheral nerves from 6 patients. Neurology (Minneap.), 20, 649-658.
Fullerton, P. M., Gilliatt, R. W., Lascelles, R. G., and Morgan-Hughes, J. A. (1965). The relation between fibre diameter and internodal length in chronic neuropathy. Journal of Physiology, 178, 26-28P.

Gilliatt, R. W. (1969). Experimental peripheral neuropathy. In Scientific Basis of Medicine Annual Reviews 1969, pp. 202-219. British Postgraduate Medical Federation. Athlone Press: London.

Lascelles, R. G., and Thomas, P. K. (1966). Changes due to age in internodal length in the sural nerve in man. Journal of Neurology, Neurosurgery and Psychiatry, 29, 40-44.

Logothetis, J., Kennedy, W. R., Ellington, A., and Williams, R. C. (1968). Cryoglobulinemic neuropathy. Incidence and clinical characteristics. Archives of Neurology, 19, 389-397.

Malkova, E. V. (1967). Syndrome of multiple neuritis in diseases of the liver. Zhurnal Nevropatologii $i$ Psikhiat rii imeni S.S. Korsakova, 67, 1189-1193.

Mayne, N. (1965). Neuropathy in the diabetic and nondiabetic populations. Lancet, 2, 1313-1316.

Megyesi, C., Samols, E., and Marks, V. (1967). Glucose tolerance and diabetes in chronic liver disease. Lancet, 2 , 1051-1055.

Morley, J. B., and Schwieger, A. C. (1968). Aspects of chronic polyneuropathy associated with myeloma. Proceedings of the Australian Association of Neurology, 5, 403-404.

Ortiz-Vásquez, J., Olmo, A., Muro, J., Villamor, J., and Barreiro, P. (1967). Neuropatia hepatica. Revista clínica éspañola añda, 104, 60-66.

Seneviratne, K. N., and Peiris, O. A. (1970). Peripheral nerve function in chronic liver disease. Journal of Neurolog $y_{\longrightarrow}$ Neurosurgery and Psychiatry, 33, 609-614.

Thomas, P. K., and Lascelles, R. G. (1966). The patholog $\mathrm{N}$ of diabetic neuropathy. Quarterly Journal of Medicine, 3옥 489-509.

Victor, M. (1965). In The Remote Effects of Cancer on the Nervous System. Edited by Lord Brain and F. H. Norrie $\mathbb{D}$ Grune and Stratton: New York.

Victor, M., Adams, R. D., and Cole, M. (1965). The acquire $\frac{8}{2}$ (non-Wilsonian) type of chronic hepatocerebral degenera tion. Medicine (Balt.), 44, 345-396. 